\title{
Spark-plasma-sintered Barium Zirconate Based Proton Conductors for Solid Oxide Fuel Cell and Hydrogen Separation Applications
}

\author{
Siwei Wanga, Yufei Liu ${ }^{b}$, Jian He ${ }^{b}$, Fanglin Chen ${ }^{c}$, Kyle S. Brinkman ${ }^{a, *}$ \\ ${ }^{a}$ Department of Materials Science and Engineering, Clemson University, Clemson, SC, \\ 29634, USA \\ ${ }^{\mathrm{b}}$ Department of Physics and Astronomy, Clemson University, Clemson, SC, 29634, USA \\ ${ }^{c}$ Department of Mechanical Engineering, University of South Carolina, Columbia, SC, \\ 29208, USA \\ *Corresponding Author: Email: ksbrink@clemson.edu
}

\begin{abstract}
Proton conducting ceramics exhibit high levels of bulk proton conductivity at intermediate temperatures $\left(500-700^{\circ} \mathrm{C}\right)$. However, this material class has not been widely utilized in energy conversion and storage applications due to the blocking behavior of the grain boundary proton conduction. A better understanding of proton conduction in these materials requires a systematic study of the sintering conditions that determine microstructure and ultimately the electrical properties. In this work, spark plasma sintering with high heating rates was employed to prepare a state-of-the-art $\mathrm{BaZr}_{0.9} \mathrm{Y}_{0.1} \mathrm{O}_{3-\delta}(\mathrm{BZY})$ proton conductor for studies focused on the behavior of proton conduction at the grain boundary interfaces. The ceramics prepared by the SPS method resulted in an ultra-fine grain size of approximately $200 \mathrm{~nm}$. The large grain boundary interfacial area was used as a "tool" to investigate the interfacial conduction in these
\end{abstract}


materials systems. Samples displayed a lowered grain boundary conductivity and a higher activation energy compared with the literature results on conventionally prepared materials. The lower bulk conductivity is interpreted with reference to polymorphs of BZY sintered at different temperatures. The combined effect led to a lower total conductivity of the SPS densified BZY ceramics.

Key words: Proton Conductor, Solid Oxide Fuel Cells, Hydrogen Separation, Spark Plasma Sintering.

\section{Introduction}

Proton conducting oxide materials have been extensively studied due to their unique proton conduction at intermediate temperatures $\left(500-700^{\circ} \mathrm{C}\right){ }^{7 ; 10 ; 11 ; 25 ; 29 ; 32}$. This materials class has demonstrated potential for use as high temperature $\mathrm{H}_{2}$ separation membranes to produce purified $\mathrm{H}_{2}$, as well as for electrolytes in next generation proton conducting solid oxide fuel cells that operate at lower temperatures than the state-of-theart oxygen ion conducting SOFCs $4 ; 5 ; 26 ; 28 ; 30 ; 32 ; 33 ; 34$. Among the various compositions of proton conductors, the $\mathrm{BaZrO}_{3}$ based compounds with different dopants and co-dopants have been widely investigated due to their high bulk proton conductivity and high chemical stability ${ }^{14 ; 20}$. Although these proton conducting oxides possess high levels of bulk conductivity, in practice, the total conductivity of such materials varies greatly depending on the synthesis methods employed. This implies that the microstructures, especially interfacial microstructures, play a key role in determining the overall performance ${ }^{27}$. Typically, large grained materials show a lower grain boundary 
resistance and a higher total conductivity. Highly resistive grain boundaries and potential space-charge induced segregations of acceptor dopants at the grain boundaries may play an important role ${ }^{9}$. The work outlined in this manuscript focused on the preparation methods that determine the microstructure of the materials, as well as the impact of the microstructure on the electrical properties.

Spark plasma sintering (SPS) provides a unique way of densifying materials at very low temperatures (at temperatures far below the melting point) via fast heating rates, which suppresses the grain growth during sintering, resulting in a refined microstructure. The lowered sintering temperature also avoids the evaporation of some volatile components during sintering. Different from conventional furnace sintering, SPS heats the materials by applying pressure and electric current directly to the sample simultaneously, so that dense ceramics can be obtained under uniform heating at relatively low sintering temperatures and in short processing times. The SPS method has been widely applied to various SOFC solid electrolytes to obtain dense sintered specimens, such as yttrium doped zirconia, $\mathrm{La}_{0.9} \mathrm{Sr}_{0.1} \mathrm{Ga}_{0.8} \mathrm{Mg}_{0.2} \mathrm{O}_{3-\delta}$, samarium doped ceria, as well as barium zirconate $^{8 ; 9 ; 12 ; 15 ; 17}$. The SPS process was observed to enhance the conductivity of electrolytes in some studies ${ }^{8 ; 15}$, while other investigations did not show any improvement in the conductivity ${ }^{9 ; 13}$. Those studies observing an enhanced conductivity reported that ultrafine grain sizes resulted in a modification in the grain boundary characteristics. A change in the grain boundary behavior from a barrier, to a promoter of proton transport was hypothesized. ${ }^{15}$. In addition, less impurities in the ceramic phase ${ }^{12}$, or improved densification of the materials were offered as additional explanations for the observed 
results ${ }^{8}$. With regards to the grain boundary conductivity in particular, recent results have indicated that samples sintered at lower temperature possess smaller grain size and higher grain boundary resistivity ${ }^{13}$. Consequently, the sintering conditions of SPS impacts the microstructure and the conductivity of the resulting samples. In this work, the small grain size induced by SPS processing resulted in a large grain boundary area that was used as a "tool" to investigate the interfacial conduction in these materials systems.

In this paper, we investigated the state-of-the-art yttrium doped barium zirconate $\mathrm{BaZr}_{0.9} \mathrm{Y}_{0.1} \mathrm{O}_{3-\delta}(\mathrm{BZY})$ proton conductor sintered by the SPS method. BZY powder was prepared by a modified pechini technique with combined EDTA-citric method resulting in nano-sized starting powders. The ceramics were densified by SPS at different sintering temperatures. The focus was on low temperature sintering in order to obtain fine-grained BZY samples. This also avoided the vaporization of the $\mathrm{Ba}$ during high temperature sintering. The phase structures and microscrostructures of the proton conductors, as well as the resulting electrical properties of the proton conducting ceramics were investigated.

\section{Experimental}

\subsection{Sample Preparation}

The proton conducting ceramic powders were prepared by a modifiled pechini method reported elsewhere ${ }^{5 ; 28 ; 30} . \mathrm{Ba}\left(\mathrm{NO}_{3}\right)_{2}$ (Alfa Aesar, 99.95\%), $\mathrm{Ce}\left(\mathrm{NO}_{3}\right)_{3} \cdot 6 \mathrm{H}_{2} \mathrm{O}$ (Alfa Aesar, 99.5\%), $\mathrm{ZrO}\left(\mathrm{NO}_{3}\right)_{2} \cdot \times \mathrm{H}_{2} \mathrm{O}$ (Alfa Aesar, 99.9\%), $\mathrm{Y}\left(\mathrm{NO}_{3}\right)_{3} \cdot 6 \mathrm{H}_{2} \mathrm{O}$ (Alfa Aesar, 99.9\%) and $\mathrm{Yb}\left(\mathrm{NO}_{3}\right)_{3} \cdot \mathrm{xH}_{2} \mathrm{O}$ (Alfa Aesar, 99.9\%) starting chemicals were dissolved in deionized water. The concentration of the metal ions in the individual nitrate was determined by 
titration. Citric acid (Alfa Aesar, 99\%) and ethylenediaminetetraacetic acid (EDTA, Alfa Aesar, 99\%) were employed as chelating and complexing agents for each composition. Ammonium hydroxide (Sigma-Aldrich, $\mathrm{NH}_{3}$ content 28.0 to $30.0 \%$ ) was added to promote the dissolution of EDTA. The metal precursors were then stoichiometrically added into the chelating and complexing agents with metal nitrates : citric acid : EDTA molar ratio $=1: 1.5: 1.2$. At this stage, ammonium hydroxide was added to keep the precursors soluble in the solution. The solution was heated and stirred for $24 \mathrm{~h}$ to achieve a fully chelated gel, followed by heat treatment in a kitchen microwave oven to assist in foaming. The gel was burned into foam during the process and the obtained ashes were subsequently fired at $600^{\circ} \mathrm{C}$ for $4 \mathrm{~h}$ in air to remove the organic residue. The powder was then calcined at $1100^{\circ} \mathrm{C}$ to form pure phase BZY powder samples.

The calcined proton conductor powder samples were then sintered by the SPS method. The powders were filled into a graphite die with a diameter of $12.7 \mathrm{~mm}$, and sintered by the SPS machine (Dr. Sinter 1020, Sumitomo Coal Mining Co.). This process was accomplished by applying a constant $4 \mathrm{MPa}$ axial pressures and an increasing $\mathrm{AC}$ current (100 $\left.\mathrm{A} \mathrm{min}^{-1}\right)$ simultaneously to the die in dynamic vacuum $(\sim 10 \mathrm{~Pa})$, while the temperature of sample was monitored by a pyrometer.

\subsection{Characterization}

The crystal structures of the calcined and sintered samples were recorded on a X-ray diffractometer (Rigaku, Japan) with graphite-monochromatized $\mathrm{CuKa}$ radiation $\left(\lambda=1.5418 \AA\right.$ ) at a scanning rate of $2^{\circ} \min ^{-1}$ in a $2 \theta$ range from 20 to $80^{\circ}$. The diffraction 
patterns were analyzed by performing Rietveld refinement using the General Structure Analysis System (GSAS) package and the graphical user interface (EXP GUI) ${ }^{24 ; 25}$. The surface microstructure and the cross-sectional morphology of the sintered pellets were characterized by scanning electron microscopy (FESEM, Zeiss Ultra). The relative density of the samples was measured by the Archimedes method. For the conductivity measurements, both surfaces of the sintered pellets were polished, painted with platinum paste (Heraeus, CL11-5349) and baked at $950^{\circ} \mathrm{C}$ for $30 \mathrm{~min}$. Platinum wires were then attached to the surface of the platinum layer. Electrical conductivity was measured using an A.C. impedance method with an A.C. amplitude of $10 \mathrm{mV}$ in the frequency range from $0.1 \mathrm{~Hz}$ to $8 \mathrm{MHz}$ via an electrochemical station with a built-in impedance analyzer (Zahner IM6 Electrochemical Workstation, ZAHNER-Electrik GmbH \& Co., Kronach, Germany). The conductivity measurement was carried out in dry air (dynamic air flowing through a silica gel and $\mathrm{CaPO}_{4}$ sand), wet air and wet $\mathrm{H}_{2}$ atmospheres (3\% water partial pressure, introduced by passing the gas through a water bubbler at room temperature) in a temperature range of $300-750^{\circ} \mathrm{C}$.

\section{Results and discussion}

\subsection{Microstructures}

Fig. 1 displays the cross-sectional microstructures of the BZY samples sintered by SPS at temperatures of 1200,1300 and $1400^{\circ} \mathrm{C}$, respectively, for $5 \mathrm{~min}$. Samples sintered at $1200^{\circ} \mathrm{C}$ exhibit a noticeable level of porosity in proximity to densified regimes. The average grain size was observed to be less than $200 \mathrm{~nm}$. The $1300^{\circ} \mathrm{C}$ and $1400^{\circ} \mathrm{C}$ sintered samples showed a dense microstructure, with grain sizes of $200 \pm 80 \mathrm{~nm}$, and $260 \pm 120 \mathrm{~nm}$ 
respectively. A close investigation revealed an oriented distribution of dense and porous layers as shown in Fig. 1(d). The porous layers were forced along the direction perpendicular to the SPS axis. The porous layer will impede the current flow and increase the magnitude of the nominal impedance. The impedance value we obtained here is thus the lower limit of the actual impedance. Higher sintering temperatures $\left(>1400^{\circ} \mathrm{C}\right)$ reduced the overall porosity in the porous layer. This is consistent with our density measurement indicating a relative density of $92.4 \%$ for the $1400^{\circ} \mathrm{C}$ sintered sample, compared to $85.5 \%$ for the $1300^{\circ} \mathrm{C}$ sintered sample. The layered distribution of denser and porous layers was

attributed to the distribution of the SPS current during sintering ${ }^{16}$. The dense layer with a lower overall resistance may have served as a conduit for current passing through the sample, partially bypassing the more resistive porous layers. For further experiments, only the sample SPS sintered at 1300 and $1400^{\circ} \mathrm{C}$ were considered. The sintering conditions of barium zirconate based materials are listed in Table 1 for reference.

\subsection{XRD analysis}

Fig. 2 shows the XRD patterns of the as-synthesized BZY powders calcined at $1100^{\circ} \mathrm{C}$ for $10 \mathrm{~h}$, and the SPS samples sintered at 1300 and $1400^{\circ} \mathrm{C}$, respectively. All of the samples display a predominant perovskite structure. In addition to the perovskite peaks, the sample sintered at $1400^{\circ} \mathrm{C}$ exhibits an extra graphite peak, attributed to the diffusion of graphite from the die into the sample surface. In the inset of Fig. 2, the peak shift between samples can be clearly identified. The increased sintering temperature resulted in a shift of the XRD peaks to a lower angle, indicating an increase of the lattice parameter with higher sintering temperature. The typical refined XRD pattern of the calcined BZY 
powder sample is shown in Fig. 3. The samples were fitted with a cubic phase Pm-3m space group, without any secondary phases present. A lattice parameters of $a=4.1989 \AA$ was obtained for the powder sample calcined at $1100^{\circ} \mathrm{C}$ from the Rietveld refinement. The lattice parameter for 1300 and $1400^{\circ} \mathrm{C}$ sintered samples were calculated to be $a=4.20237$ and $a=4.21195 \AA$, respectively. The observed peak shift has been confirmed by adding the peaks of an $\mathrm{Al}$ sample holder as the calibration standard. It is known that increasing the effective $\mathrm{Y}$ content in the unit cell increases the lattice parameter due to a combination of the difference in ionic radii and an increased oxygen vacancy content. An additional explanation was proposed by J. Irvine that two variants of BZY, both with cubic perovskite $P m-3 m$ structure, with $\alpha$-phase exhibits smaller unit cell and lower protonic conductivity than the $\beta$-phase ${ }^{1}$. It is believed that the cross substitution of $\mathrm{Y}$ from B-sites onto the A-sites, including charge compensation which increases oxygen occupancy leads the increased unit cell size. Surface stress that may exist in the polished sample surfaces that would likely affect the lattice parameter should be not significant and have been ruled out as the origin of the peak shift.

\subsection{Conductivity}

Fig. 4 shows a Nyquist plot of the BZY sample impedance spectrum. The impedance spectrum typically has three semi-circles corresponding to the bulk, grain boundary and electrode responses from high to low frequencies, which can be fitted by a parallel RCPE (constant phase element) equivalent circuit model. The inset in Fig. 4 is the R-CPE model that was used to fit the impedance spectra in the present work. 
Fig.5 shows the Arrhenius plots of the total conductivity as a function of testing temperature for the BZY sample sintered at different temperatures. The tests were conducted in dry air (Fig. 5(a)), wet air (Fig. 5(b)), wet $\mathrm{N}_{2}$ (Fig. 5(c)), and wet $\mathrm{H}_{2}$ (Fig. $5(\mathrm{~d})$ ), respectively. Overall the conductivity values of the sample sintered at $1300^{\circ} \mathrm{C}$ and $1400^{\circ} \mathrm{C}$ are similar. However, the sample sintered at $1400^{\circ} \mathrm{C}$ displayed slightly higher values of conductivity. This behavior is more predominant at higher temperatures.

The activation energy $\left(E_{a}\right)$ of the samples was obtained by linear fitting the slopes of the Arrhenius plots from equation (1):

$\sigma \mathrm{T}=\mathrm{A} * \exp \left(-\frac{E_{a}}{R T}\right)$

where $\sigma$ is the conductivity, $\mathrm{T}$ is the temperature in $\mathrm{K}, \mathrm{A}$ is constant, $\mathrm{R}$ is the gas constant. The activation energy is lower for the BZY sample sintered at $1300^{\circ} \mathrm{C}$, especially in the high temperature regime and reducing atmospheres (Fig. 5(d)).

For comparison, the total conductivity of the BZY sample SPS sintered at $1400^{\circ} \mathrm{C}$ in different atmospheres is presented in Fig. 6 . In the temperature regime below $600^{\circ} \mathrm{C}$, the sample tested in wet $\mathrm{H}_{2}$ exhibited the highest conductivity and lowest activation energy, while the sample tested in dry air possessed the highest activation energy. The conductivity and activation energy values of this material, which are characteristic of proton conduction, are presented in Table 1. 
Fig. 7 shows the Arrhenius plots of the bulk and grain boundary conductivity of samples tested in wet $\mathrm{N}_{2}$. It was observed that the sample sintered at $1400^{\circ} \mathrm{C}$ displayed higher bulk and higher grain boundary conductivity than the sample sintered at $1300^{\circ} \mathrm{C}$.

Fig. 8 shows the bulk and grain boundary (GB) conductivity measured in wet air and wet $\mathrm{H}_{2}$ for the sample SPS sintered at $1400^{\circ} \mathrm{C}$. The trends observed in the bulk and grain boundary conductivity were similar to those observed for the total conductivity. The bulk and grain boundary conductivity values were smaller in wet $\mathrm{H}_{2}$, with lower activation energy due to the significant p-type electronic conduction present in oxidizing atmospheres ${ }^{17}$. The activation energy of the grain boundary conduction was observed to be higher than the bulk conduction, which results in the grain boundary conductivity becoming dominant at higher temperatures. This observation is consistent with the literature results shown in Table 1.

It is noted that the conductivity and activation energy of the samples prepared in this work were lower than the Barium Zirconate based materials prepared elsewhere. The conductivity values of our samples sintered via the SPS method is $\sim 2-3$ orders of magnitude lower compared to literature results on varying $\mathrm{BaZr}_{1-\mathrm{x}} \mathrm{Y}_{\mathrm{x}} \mathrm{O}_{3-\delta}$ compositions. For example, $\mathrm{BaZr}_{0.8} \mathrm{Y}_{2} \mathrm{O}_{3-\delta}$ (BZY20) samples prepared by a solid state reaction method sintered in the range of $1325-1600^{\circ} \mathrm{C}$ in the presence of sintering aids displayed $\sim 2-3$ order of magnitude higher conductivity than the present work. ${ }^{21 ; 23}$ In addition, BZY materials sintered via a solid state reaction method at $1600^{\circ} \mathrm{C}$ for $24 \mathrm{~h}$ resulted in conductivity values $\sim 4$ order of magnitude greater than the present work ${ }^{31}$. It is apparent 
that the effective $\mathrm{Y}$ dopant concentration in the structure should be taken into consideration when interpreting the results. The samples prepared in this study contained only $10 \%$ Y dopant, and the conductivity values were similar with BZY samples sintered at $1450^{\circ} \mathrm{C}$ by a sol-gel method, which has a typical grain size of $200-500 \mathrm{~nm}^{19}$.

The observed reduction in grain boundary conductivity can be understood by considering the SPS induced microstructure, which consists of a large number of grain boundaries due to the lowed sintering temperature and short sintering time of the SPS method. As can be seen from the SEM pictures, the grain sizes of our samples was approximately 200-400 nm, compared to $\sim 1 \mu \mathrm{m}$ for the samples prepared via the other methods mentioned above. At the same time, the grain boundary and bulk activation energy value of the sample in our experiment was also higher than the literature results indicating an additional electronic conduction component along with the ionic conduction in our materials.

The exact reason for the lowered bulk conductivity is not clear at present. It was observed by Irvine et. al., that higher sintering temperatures produce more of a $\beta$-phase in polymorphic BZY. The $\mathrm{Y}$ doping on the A-site reduces the overall oxygen vacancy content and replaces negative charged defects on the $\mathrm{B}$-site, $\mathrm{Y}_{\mathrm{Zr}}^{\prime}$, with positively charged defects on the $\mathrm{A}$ site $\mathrm{Y}^{\bullet}$ Ba, decreasing defect association ${ }^{1 ; 3 ; 17}$. We attempted to look at this phenomenon in our work, but due to the low resolution of the XRD used in our experiments, it was difficult to observe differences due to these effects in our samples. Future work will involve the use of more sensitive neutron powder diffraction 
experiments to study this phenomenon. However, we currently believe the $\beta$-phase may contribute to the change in the bulk conductivity for our samples. For example, increasing the SPS treatment temperature up to $1700^{\circ} \mathrm{C}$ for $5 \mathrm{~min}$ for BZY samples prepared by a solid state reaction method resulted in conductivity values of $\sim 10^{-3} \mathrm{~S} \mathrm{~cm}^{-1}$ at $600^{\circ} \mathrm{C}^{18}$. These values of conductivity are $\sim 3$ orders of magnitude higher than our results and comparable to the best results reported on this material system. At present, it is believed that the high sintering temperature is more favorable for the formation of a $\beta$ phase which is expected to possess higher proton conductivity.

\section{Conclusions:}

$\mathrm{BaZr}_{0.9} \mathrm{Y}_{0.1} \mathrm{O}_{3}$ ceramic powders were successfully prepared by a modified pechini method at $1100^{\circ} \mathrm{C}$. SPS of the samples at $1300-1400^{\circ} \mathrm{C}$ for 5 min was sufficient to obtain densified, fine grained microstructure due to the enhanced kinetics for SPS densification. The sintered samples were pure phase, and exhibited an increase in the lattice parameter with increasing sintering temperature. The sample sintered at $1400^{\circ} \mathrm{C}$ exhibited higher conductivity than samples sintered at $1300^{\circ} \mathrm{C}$. The $1400^{\circ} \mathrm{C}$ sintered sample displayed a lower grain boundary conductivity of $2.4 \times 10^{-6} \mathrm{~S} \mathrm{~cm}^{-1}$ at $500^{\circ} \mathrm{C}$, and a higher activation energy of $1.28 \mathrm{eV}$, compared with literature results from conventionally prepared materials, which was due to the ultra-fined microstructure of the sample prepared by SPS. This large grain boundary area was used as a "tool" to investigate the interfacial conduction in these materials systems. The bulk conductivity was also lower than the reported data, with values approaching $1.6 \times 10^{-6} \mathrm{~S} \mathrm{~cm}^{-1}$ at $500^{\circ} \mathrm{C}$, which was ascribed to 
variations in the relative amounts of the $\beta$-phase in BZY polymorphs sintered at lower temperatures.

\section{Acknowledgement}

The authors acknowledge financial support from an Energy Frontier Research Center on

Science Based Nano-Structure Design and Synthesis of Heterogeneous Functional Materials for Energy Systems (HeteroFoaM Center) funded by the U.S. Department of Energy, Office of Science, Office of Basic Energy Sciences (Award no. DE-SC0001061). K. Brinkman and J. He also wishes to acknowledge a 2014 Clemson TIGER Grant on Materials and Processes for Natural Gas Utilization.

\section{References}

${ }^{1}$ A. K. Azad, C. Savaniu, S. Tao, S. Duval, P. Holtappels, R. M. Ibberson, andJ. T. S. Irvine, "Structural origins of the differing grain conductivity values in $\mathrm{BaZr}_{0.9} \mathrm{Y}_{0.1} \mathrm{O}_{2.95}$ and indication of novel approach to counter defect association," J. Mater. Chem., 18[29] 3414-18 (2008).

${ }^{2}$ R. B. Cervera, Y. Oyama, S. Miyoshi, K. Kobayashi, T. Yagi, andS. Yamaguchi, "Structural study and proton transport of bulk nanograined $\mathrm{Y}$-doped $\mathrm{BaZrO}_{3}$ oxide protonics materials," Solid State Ionics, 179[7-8] 236-42 (2008).

${ }^{3}$ S. B. C. Duval, P. Holtappels, U. F. Vogt, U. Stimming, andT. Graule, "Characterisation of $\mathrm{BaZr}_{0.9} \mathrm{Y}_{0.1} \mathrm{O}_{3-\delta}$ Prepared by Three Different Synthesis Methods: Study of the Sinterability and the Conductivity," Fuel Cells, 9[5] 613-21 (2009).

${ }^{4}$ E. Fabbri, L. Bi, H. Tanaka, D. Pergolesi, andE. Traversa, "Chemically Stable Pr and Y CoDoped Barium Zirconate Electrolytes with High Proton Conductivity for IntermediateTemperature Solid Oxide Fuel Cells," Adv. Funct. Mater., 21[1] 158-66 (2011).

${ }^{5}$ S. Fang, S. Wang, K. S. Brinkman, and F. Chen, "A sinteractive Ni-BaZr $\mathrm{r}_{0.8} \mathrm{Y}_{0.2} \mathrm{O}_{3-\delta}$ composite membrane for hydrogen separation," J. Mater. Chem. A, 2[16] 5825-33 (2014).

${ }^{6}$ F. Iguchi, T. Yamada, N. Sata, T. Tsurui, andH. Yugami, "The influence of grain structures on the electrical conductivity of a $\mathrm{BaZr}_{0.95} \mathrm{Y}_{0.05} \mathrm{O}_{3}$ proton conductor," Solid State Ionics, 177[26-32] 2381-84 (2006).

${ }^{7}$ H. Iwahara, T. Esaka, H. Uchida, and N. Maeda, "Proton conduction in sintered oxides and its application to steam electrolysis for hydrogen production," Solid State Ionics, 3-4 359-63 (1981).

${ }^{8}$ Y. Jing, Y. Ma, J. Patakangas, B. Zhu, M. Johnsson, M. E. Cura, andP. Lund, "Enhanced conductivity of SDC based nanocomposite electrolyte by spark plasma sintering," Int. J. Hydrogen Energy, 39[26] 14391-96. 
${ }^{9}$ C. Kjølseth, H. Fjeld, Ø. Prytz, P. I. Dahl, C. Estournès, R. Haugsrud, andT. Norby, "Spacecharge theory applied to the grain boundary impedance of proton conducting $\mathrm{BaZr}_{0.9} \mathrm{Y}_{0.1} \mathrm{O}_{3-\delta}$," Solid State Ionics, 181[5-7] 268-75 (2010).

${ }^{10}$ K. D. Kreuer, "Proton-conducting oxides," Annu. Rev. Mater. Res., 33 333-59 (2003).

${ }^{11} \mathrm{R}$. Lan and S. Tao, "Novel Proton Conductors in the Layered Oxide Material $\mathrm{Li}_{\mathrm{x}} 1 \mathrm{Al}_{0.5} \mathrm{Co}_{0.5} \mathrm{O}_{2}$," Adv. Energy Mater., 4[7] 1301683 (2014).

${ }^{12}$ B. Liu and Y. Zhang, "La $\mathrm{La}_{0.9} \mathrm{Sr}_{0.1} \mathrm{Ga}_{0.8} \mathrm{Mg}_{0.2} \mathrm{O}_{3-\delta}$ sintered by spark plasma sintering (SPS) for intermediate temperature SOFC electrolyte," J. Alloys Compd., 458[1-2] 383-89 (2008).

${ }^{13}$ F. Maglia, U. Anselmi-Tamburini, G. Chiodelli, H. E. Çamurlu, M. Dapiaggi, andZ. A. Munir, "Electrical, structural, and microstructural characterization of nanometric $\mathrm{La}_{0.9} \mathrm{Sr}_{0.1} \mathrm{Ga}_{0.8} \mathrm{Mg}_{0.2} \mathrm{O}_{3-\delta}$ (LSGM) prepared by high-pressure spark plasma sintering," Solid State Ionics, 180[1] 36-40 (2009).

${ }^{14}$ D. Pergolesi, E. Fabbri, A. D’Epifanio, E. Di Bartolomeo, A. Tebano, S. Sanna, S. Licoccia, G. Balestrino, andE. Traversa, "High proton conduction in grain-boundary-free yttriumdoped barium zirconate films grown by pulsed laser deposition," Nat. Mater., 9[10] 84652 (2010).

${ }^{15}$ K. Rajeswari, M. B. Suresh, D. Chakravarty, D. Das, andR. Johnson, "Effect of nano-grain size on the ionic conductivity of spark plasma sintered 8YSZ electrolyte," Int. J. Hydrogen Energy, 37[1] 511-17 (2012).

${ }^{16}$ C. Ramirez, F. M. Figueiredo, P. Miranzo, P. Poza, andM. I. Osendi, "Graphene nanoplatelet/silicon nitride composites with high electrical conductivity," Carbon, 50[10] 3607-15 (2012).

${ }^{17}$ S. Ricote, N. Bonanos, A. Manerbino, andW. G. Coors, "Conductivity study of dense $\mathrm{BaCe}_{\mathrm{x}} \mathrm{Zr}_{(0.9-\mathrm{x})} \mathrm{Y}_{0.1} \mathrm{O}_{(3-\delta)}$ prepared by solid state reactive sintering at $1500{ }^{\circ} \mathrm{C}, "$ Int. J. Hydrogen Energy, 37[9] 7954-61 (2012).

${ }^{18}$ S. Ricote, N. Bonanos, H. J. Wang, andB. A. Boukamp, "Conductivity study of dense $\mathrm{BaZr}_{0.9} \mathrm{Y}_{0.1} \mathrm{O}_{(3-\delta)}$ obtained by spark plasma sintering," Solid State Ionics, 213[0] 36-41 (2012).

${ }^{19}$ C. D. Savaniu, J. Canales-Vazquez, andJ. T. S. Irvine, "Investigation of proton conducting $\mathrm{BaZr}_{0.9} \mathrm{Y}_{0.1} \mathrm{O}_{2.95}: \mathrm{BaCe}_{0.9} \mathrm{Y}_{0.1} \mathrm{O}_{2.95}$ core-shell structures," J. Mater. Chem., 15[5] 598-604 (2005).

${ }^{20}$ W. Sun, M. Liu, andW. Liu, "Chemically Stable Yttrium and Tin Co-Doped Barium Zirconate Electrolyte for Next Generation High Performance Proton-Conducting Solid Oxide Fuel Cells," Adv. Energy Mater., 3[8] 1041-50 (2013).

${ }^{21}$ Z. Sun, E. Fabbri, L. Bi, andE. Traversa, "Lowering grain boundary resistance of $\mathrm{BaZr}_{0.8} \mathrm{Y}_{0.2} \mathrm{O}_{3-\delta}$ with $\mathrm{LiNO}_{3}$ sintering-aid improves proton conductivity for fuel cell operation," Phys. Chem. Chem. Phys., 13[17] 7692-700 (2011).

${ }^{22} \mathrm{~S}$. Tao and J. T. S. Irvine, "Conductivity studies of dense yttrium-doped $\mathrm{BaZrO}_{3}$ sintered at $1325^{\circ}$ C," J. Solid State Chem., 180[12] 3493-503 (2007).

${ }^{23}$ S. W. Tao and J. T. S. Irvine, "A Stable, Easily Sintered Proton- Conducting Oxide Electrolyte for Moderate-Temperature Fuel Cells and Electrolyzers," Advanced Materials, 18[12] 1581-84 (2006).

${ }^{24}$ B. Toby, "EXPGUI, a graphical user interface for GSAS," J. Appl. Crystallogr., 34[2] 210-13 (2001).

${ }^{25}$ S. Wang, Y. Chen, S. Fang, L. Zhang, M. Tang, K. An, K. S. Brinkman, andF. Chen, "Novel Chemically Stable $\mathrm{Ba}_{3} \mathrm{Ca}_{1.18} \mathrm{Nb}_{1.82-\mathrm{x}} \mathrm{Y}_{\mathrm{x}} \mathrm{O}_{9-\delta}$ Proton Conductor: Improved Proton Conductivity through Tailored Cation Ordering," Chem. Mater., 26[6] 2021-29 (2014).

${ }^{26}$ S. Wang, L. Zhang, Z. Yang, L. Zhang, S. Fang, K. Brinkman, andF. Chen, "Two-step cosintering method to fabricate anode-supported $\mathrm{Ba}_{3} \mathrm{Ca}_{1.18} \mathrm{Nb}_{1.82} \mathrm{O}_{9-\delta}$ proton-conducting solid oxide fuel cells," J. Power Sources, 215 221-26 (2012). 
${ }^{27}$ S. Wang, L. Zhang, L. Zhang, K. Brinkman, andF. Chen, "Two-step sintering of ultrafinegrained barium cerate proton conducting ceramics," Electrochim. Acta, 87[0] 194-200 (2013).

${ }^{28}$ S. Wang, F. Zhao, L. Zhang, K. Brinkman, andF. Chen, "Stability and electrical property of Ba1-xSrxCe0.8Y0.2O3- $\delta$ high temperature proton conductor," J. Alloys Compd., 506[1] 263-67 (2010).

${ }^{29}$ S. Wang, F. Zhao, L. Zhang, K. Brinkman, andF. Chen, "Doping effects on complex perovskite $\mathrm{Ba}_{3} \mathrm{Ca}_{1.18} \mathrm{Nb}_{1.82} \mathrm{O}_{9-\delta}$ intermediate temperature proton conductor," J. Power Sources, 196[19] 7917-23 (2011).

${ }^{30} \mathrm{~S}$. Wang, F. Zhao, L. Zhang, andF. Chen, "Synthesis of $\mathrm{BaCe}_{0.7} \mathrm{Zr}_{0.1} \mathrm{Y}_{0.1} \mathrm{Yb}_{0.1} \mathrm{O}_{3-\delta}$ proton conducting ceramic by a modified Pechini method," Solid State Ionics, 213[0] 29-35 (2012).

${ }^{31}$ Y. Yamazaki, R. Hernandez-Sanchez, andS. M. Haile, "High Total Proton Conductivity in Large-Grained Yttrium-Doped Barium Zirconate," Chem. Mater., 21[13] 2755-62 (2009).

${ }^{32}$ L. Yang, S. Z. Wang, K. Blinn, M. F. Liu, Z. Liu, Z. Cheng, andM. L. Liu, "Enhanced Sulfur and Coking Tolerance of a Mixed Ion Conductor for SOFCs: $\mathrm{BaZr}_{0.1} \mathrm{Ce}_{0.7} \mathrm{Y}_{0.2-\mathrm{x}} \mathrm{Yb}_{\mathrm{x}} \mathrm{O}_{3-\delta}$," Science, 326[5949] 126-29 (2009).

${ }^{33}$ L. Zhang, Z. Mao, J. D. Thomason, S. Wang, andK. Huang, "Synthesis of a Homogeneously Porous Solid Oxide Matrix with Tunable Porosity and Pore Size," J. Am. Ceram. Soc., 95[6] 1832-37 (2012).

${ }^{34}$ F. Zhao, S. Wang, L. Dixon, andF. Chen, "Novel BaCe0.7In0.2Yb0.1O3- $\delta$ proton conductor as electrolyte for intermediate temperature solid oxide fuel cells," J. Power Sources, 196[18] 7500-04 (2011). 
Table 1 Conductivity values (at $500^{\circ} \mathrm{C}$ ) and Activation Energy values of BZY samples.

\begin{tabular}{|c|c|c|c|c|c|c|c|c|}
\hline Sample & $\begin{array}{l}\text { Sintering } \\
\text { Condition }\end{array}$ & $\begin{array}{l}\text { Grain } \\
\text { Size } \\
(\mu \mathrm{m})\end{array}$ & $\begin{array}{l}\text { Total }(S \\
\left.\mathbf{c m}^{-1}\right)\end{array}$ & $\begin{array}{l}\text { Grain } \\
\text { Boundary } \\
\left(\mathrm{S} \mathrm{cm}^{-1}\right)\end{array}$ & $\begin{array}{l}\text { Bulk (S } \\
\left.\text { cm }^{-1}\right)\end{array}$ & Atmos. & $\begin{array}{l}\mathbf{E a} \\
(\mathrm{eV})\end{array}$ & Ref. \\
\hline BZY10 & $\begin{array}{l}1400^{\circ} \mathrm{C}, \\
5 \mathrm{~min}, \mathrm{SPS}, \\
\text { nitrates }\end{array}$ & 0.26 & $9.4 \times 10^{-7}$ & $2.4 \times 10^{-6}$ & $1.6 \times 10^{-6}$ & Wet $\mathrm{H}_{2}$ & 1.20 & This work \\
\hline BZY10 & $\begin{array}{l}1450^{\circ} \mathrm{C}, 6 \mathrm{~h}, \\
\text { acetates }\end{array}$ & $0.2-0.5$ & $7.5 \times 10^{-6}$ & $7.8 \times 10^{-6}$ & $2.6 \times 10^{-4}$ & $\begin{array}{l}\text { Wet } 5 \% \\
\mathrm{H}_{2} / \mathrm{Ar}\end{array}$ & $\begin{array}{l}0.21 \\
\text { (bulk), } \\
0.72 \\
(\mathrm{gb})\end{array}$ & Irvine ${ }^{19}$ \\
\hline BZY10 & $\begin{array}{l}1700^{\circ} \mathrm{C}, \\
5 \mathrm{~min}, \mathrm{SPS}, \\
\text { SSR }\end{array}$ & 0.23 & $1.0 \times 10^{-3}$ & $4.4 \times 10^{-4}$ & $8.4 \times 10^{-4}$ & $\begin{array}{l}\text { Wet } 9 \% \\
\mathrm{H}_{2} / \mathrm{N}_{2}\end{array}$ & $\begin{array}{l}0.43 \\
\text { (bulk), } \\
0.64 \\
(\mathrm{gb})\end{array}$ & Ricote $^{18}$ \\
\hline BZY05 & $1800^{\circ} \mathrm{C}, 20 \mathrm{~h}$ & 0.67 & - & $8.2 \times 10^{-3}$ & $1.7 \times 10^{-3}$ & wet air & - & Iguchi $^{6}$ \\
\hline $\begin{array}{l}\text { BZY20- } \\
\mathrm{ZnO}\end{array}$ & $\begin{array}{l}1325^{\circ} \mathrm{C}, 10 \\
\mathrm{~h},\end{array}$ & - & $4.8 \times 10^{-4}$ & $1.5 \times 10^{-3}$ & $7.6 \times 10^{-4}$ & $\begin{array}{l}\text { Wet } 5 \% \\
\mathrm{H}_{2} / \mathrm{Ar}\end{array}$ & 0.23 & Irvine $^{22}$ \\
\hline $\begin{array}{l}\text { BZY20- } \\
\mathbf{L i}\end{array}$ & $\begin{array}{l}1600^{\circ} \mathrm{C}, 6 \mathrm{~h} \text {, } \\
\text { wet } \\
\text { chemistry } \\
\text { nitrates }\end{array}$ & 0.43 & $2.7 \times 10^{-3}$ & $\begin{array}{l}7.4 \times 10^{-4} \\
\left(350^{\circ} \mathrm{C}\right)\end{array}$ & $\begin{array}{l}3.5 \times 10^{-3} \\
\left(350^{\circ} \mathrm{C}\right)\end{array}$ & $\begin{array}{l}\text { Wet } \\
10 \% \\
\mathrm{H}_{2} / \mathrm{Ar}\end{array}$ & 0.48 & Traversa $^{21}$ \\
\hline BZY20 & $\begin{array}{l}1600^{\circ} \mathrm{C}, 24 \mathrm{~h} \\
\text { Reactive } \\
\text { sintering, } \\
\text { nitrates }\end{array}$ & 1 & $2.2 \times 10^{-2}$ & $\begin{array}{l}1.0 \times 10^{-2} \\
\left(350^{\circ} \mathrm{C}\right)\end{array}$ & $\begin{array}{l}1.2 \times 10^{-2} \\
\left(350^{\circ} \mathrm{C}\right)\end{array}$ & $\begin{array}{l}\text { wet } \mathrm{N}_{2} \\
\text { or } \mathrm{Ar}\end{array}$ & - & Haile $^{31}$ \\
\hline BZY20 & $\begin{array}{l}1500^{\circ} \mathrm{C}, 20 \\
\text { h, alkoxides }\end{array}$ & 0.2 & $4 \times 10^{-3}$ & - & - & Wet Ar & 0.54 & Cervera $^{2}$ \\
\hline
\end{tabular}




\section{Figure Captions}

Fig. 1 SEM cross-section pictures of BZY samples SPS sintered at different temperatures for $5 \mathrm{~min}$, (a) $1200^{\circ} \mathrm{C}$, (b) $1300^{\circ} \mathrm{C}$, and (c) $1400^{\circ} \mathrm{C}$. (d) The low magnified SEM picture of the sample sintered at $1300^{\circ} \mathrm{C}$, where layered structure can be observed.

Fig. 2 XRD patterns of the as synthesized BZY powders calcined at $1100^{\circ} \mathrm{C}$ (black line), and polished surface XRD patterns of samples spark plasma sintered 1300 and $1400^{\circ} \mathrm{C}$ for $5 \mathrm{~min}$. Inset is the expanded view of (110) peaks for the samples.

Fig. 3 Typical Rietveld refined XRD patterns of the as calcined BZY sample, with Pm$3 m$ space group, $\mathrm{R}_{\mathrm{wp}}=6.32 \%, \mathrm{R}_{\mathrm{p}}=5.46 \%, \chi^{2}=1.525$.

Fig. 4 Nyquist plots for BZY sample tested in dry air at $348^{\circ} \mathrm{C}$. The fitting was achieved by using a series of R-CPE model.

Fig. 5 Total conductivity of the BZY samples sintered at 1300 and $1400^{\circ} \mathrm{C}$ measured in different atmospheres.

Fig. 6 Total conductivity of the BZY samples sintered at $1400^{\circ} \mathrm{C}$ in different atmospheres.

Fig. 7 Comparison of the bulk and grain boundary (GB) conductivity in wet $\mathrm{N}_{2}$ for the BZY samples sintering at 1300 and $1400^{\circ} \mathrm{C}$.

Fig. 8 Bulk and grain boundary (GB) conductivity for BZY sample sintered at $1400^{\circ} \mathrm{C}$. 
Fig. 1

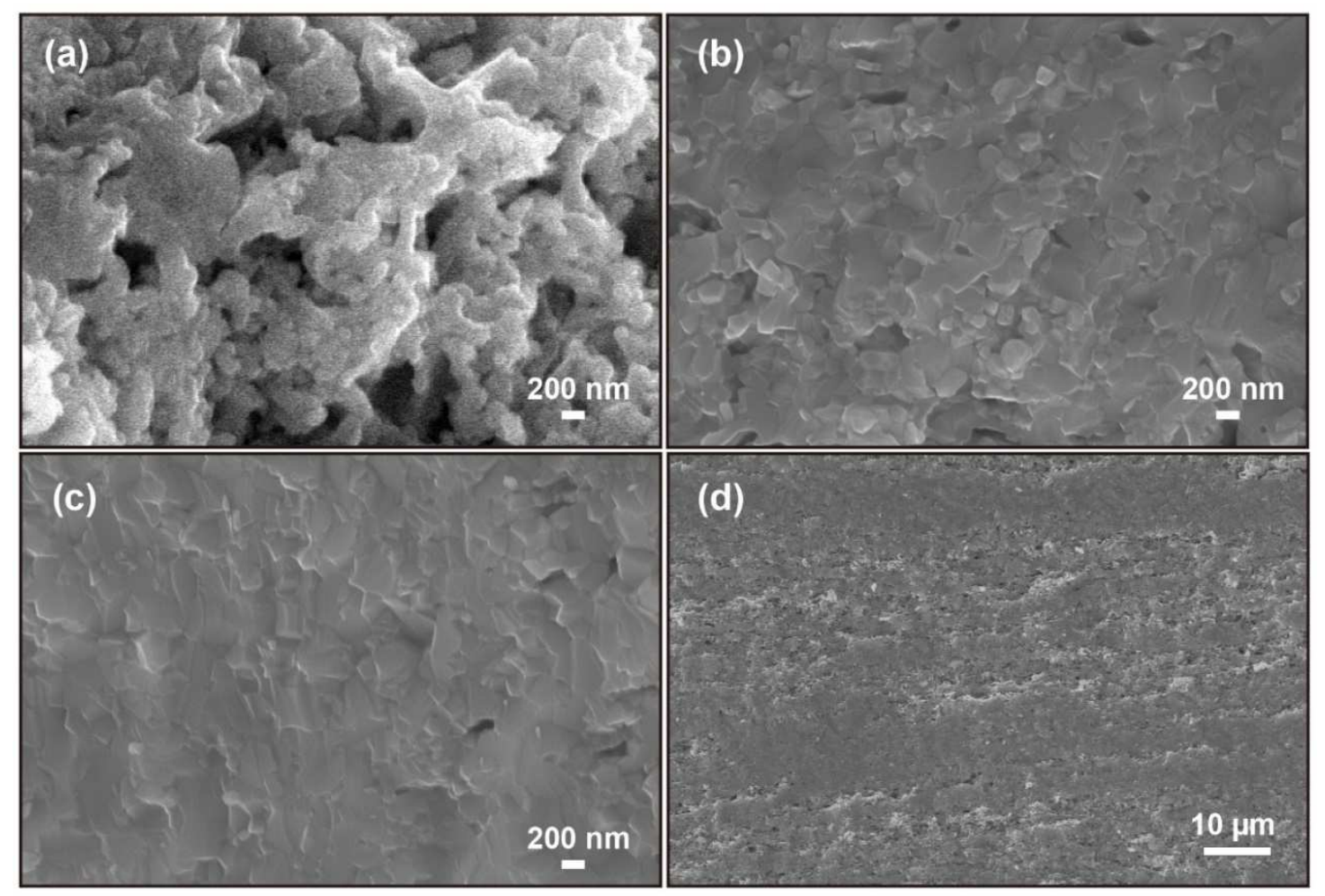

Fig. 1 SEM cross-section pictures of BZY samples SPS sintered at different temperatures for $5 \mathrm{~min}$, (a) $1200^{\circ} \mathrm{C}$, (b) $1300^{\circ} \mathrm{C}$, and (c) $1400^{\circ} \mathrm{C}$. (d) The low magnified SEM picture of the sample sintered at $1300^{\circ} \mathrm{C}$, where layered structure can be observed. 
Fig. 2

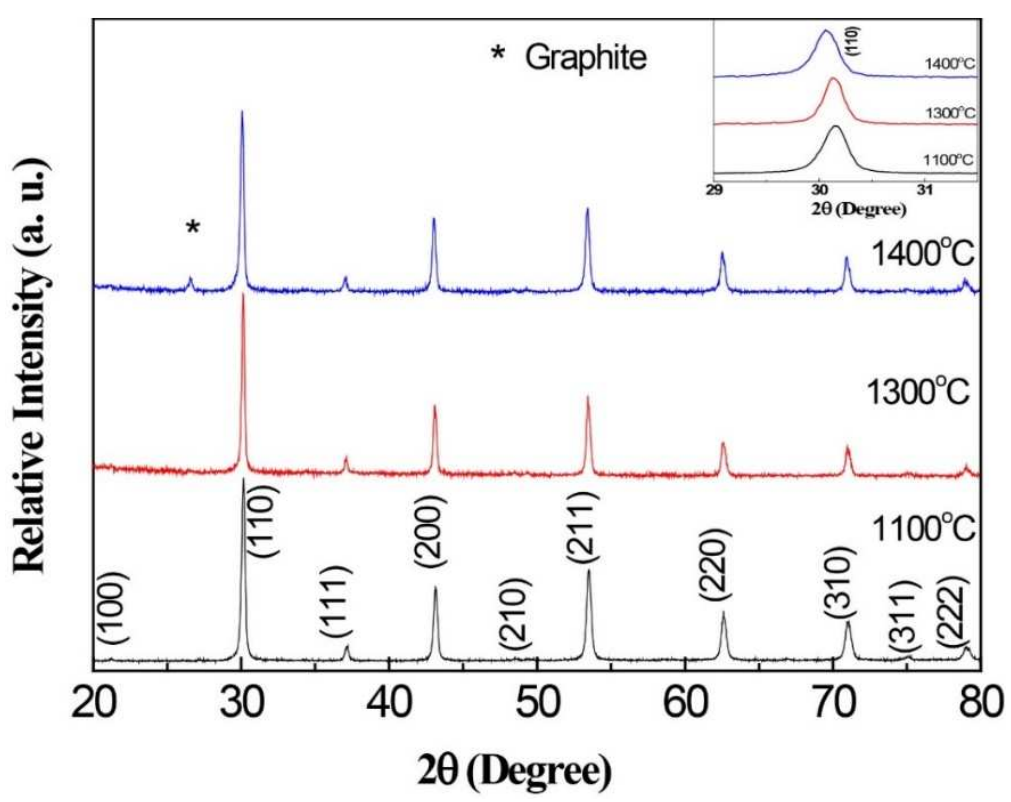

Fig. 2 XRD patterns of the as synthesized BZY powders calcined at $1100^{\circ} \mathrm{C}$ (black line), and polished surface XRD patterns of samples spark plasma sintered 1300 and $1400^{\circ} \mathrm{C}$ for $5 \mathrm{~min}$. Inset is the expanded view of (110) peaks for the samples. 
Fig. 3

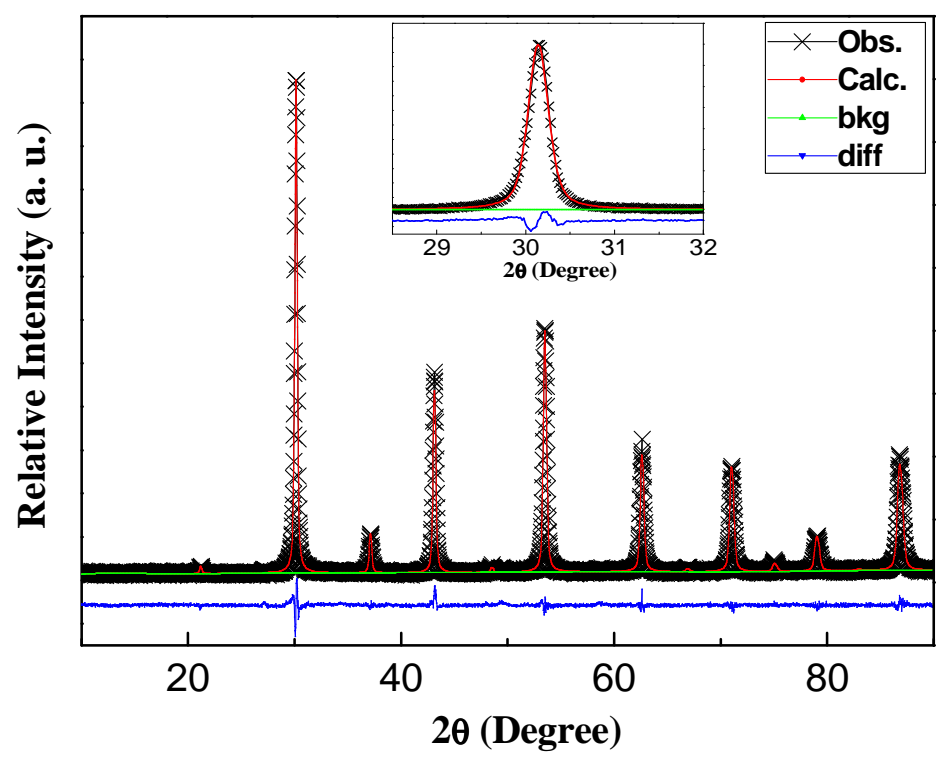

Fig. 3 Typical Rietveld refined XRD patterns of the as calcined BZY sample, with Pm$3 m$ space group, $\mathrm{R}_{\mathrm{wp}}=6.32 \%, \mathrm{R}_{\mathrm{p}}=5.46 \%, \chi^{2}=1.525$. 
Fig. 4

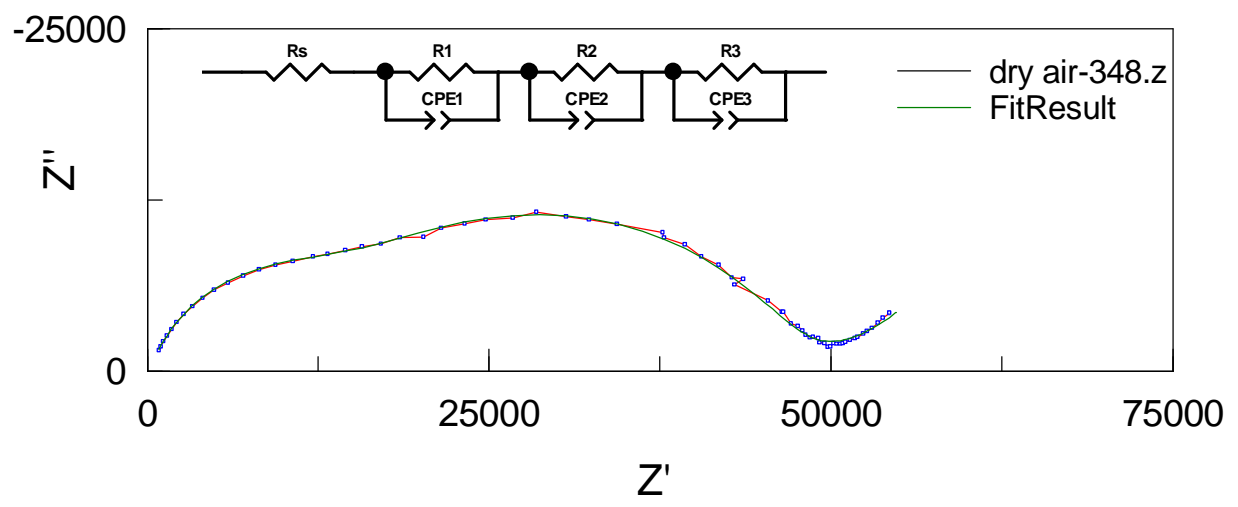

Fig. 4 Nyquist plots for BZY sample tested in dry air at $348^{\circ} \mathrm{C}$. The fitting was achieved by using a series of R-CPE model. 
Fig. 5
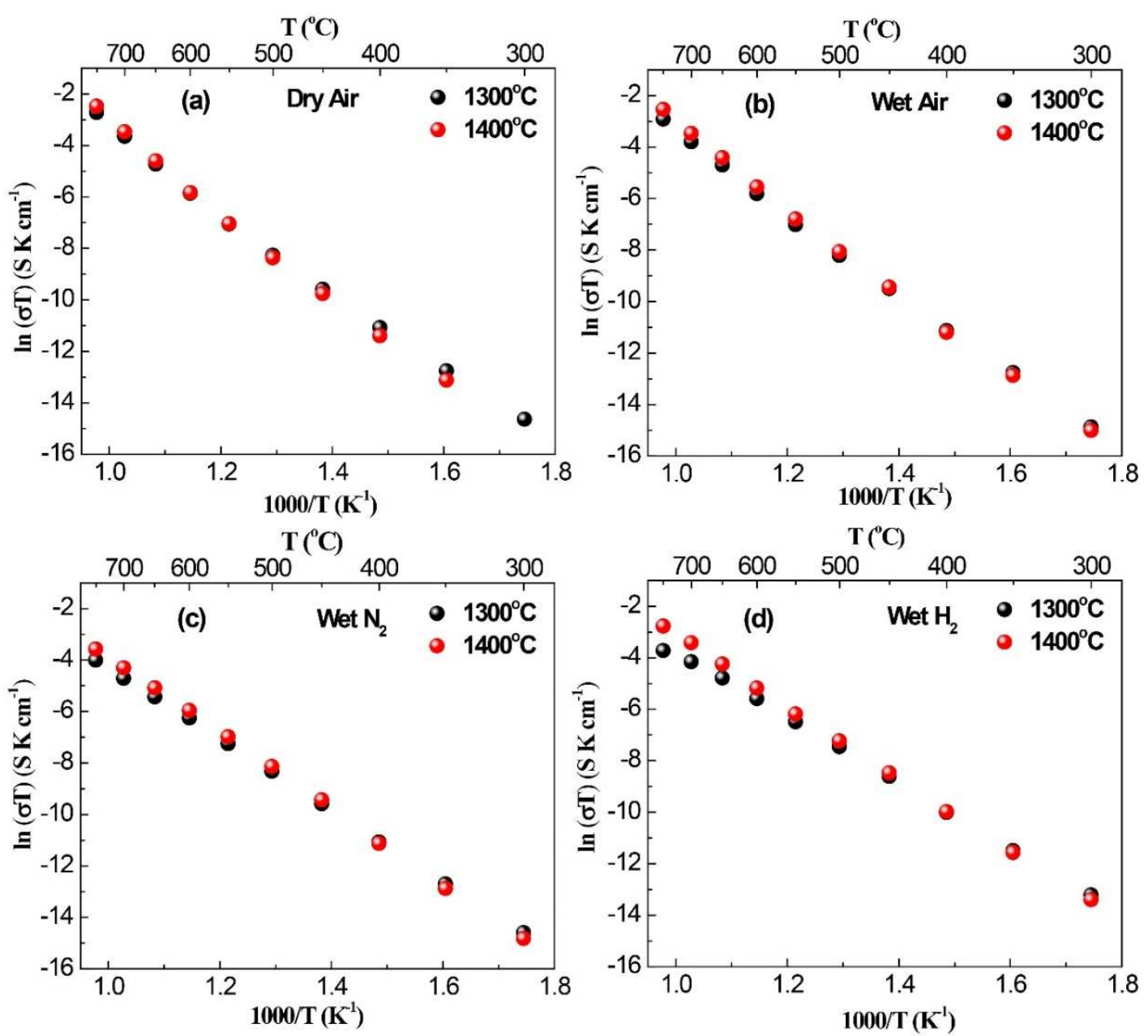

Fig. 5 Total conductivity of the BZY samples sintered at 1300 and $1400^{\circ} \mathrm{C}$ measured in different atmospheres. 
Fig. 6

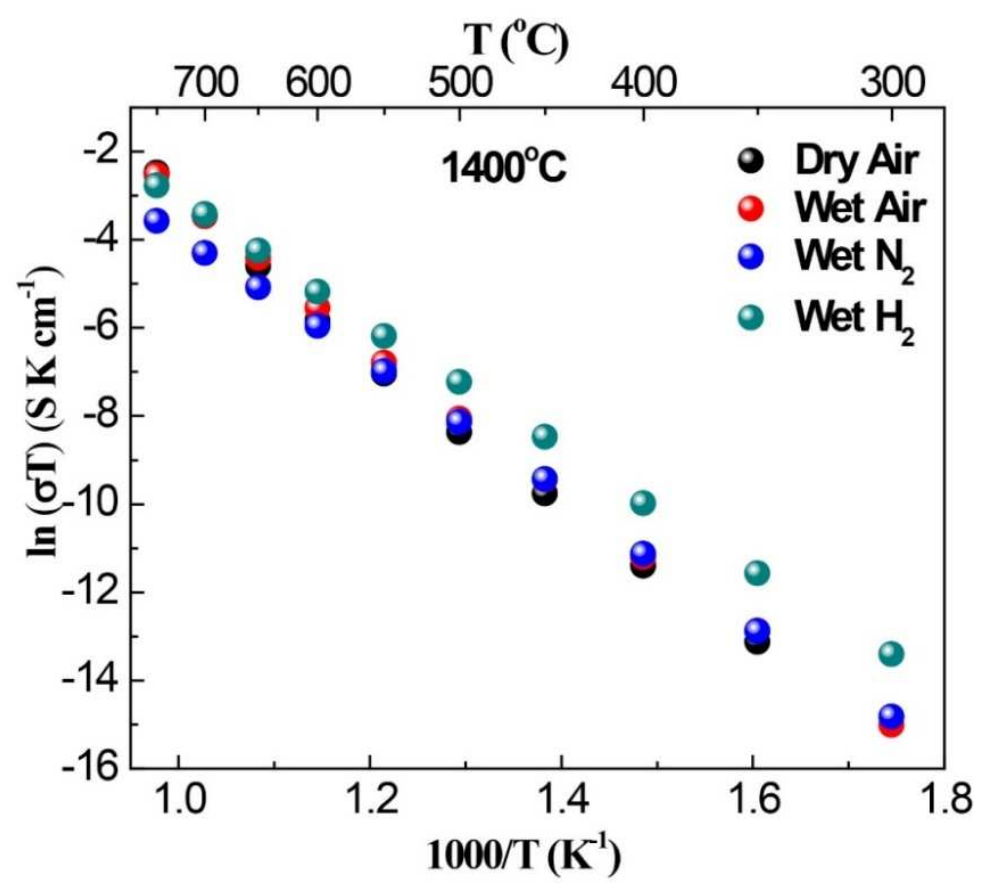

Fig. 6 Total conductivity of the BZY samples sintered at $1400^{\circ} \mathrm{C}$ in different atmospheres. 
Fig. 7

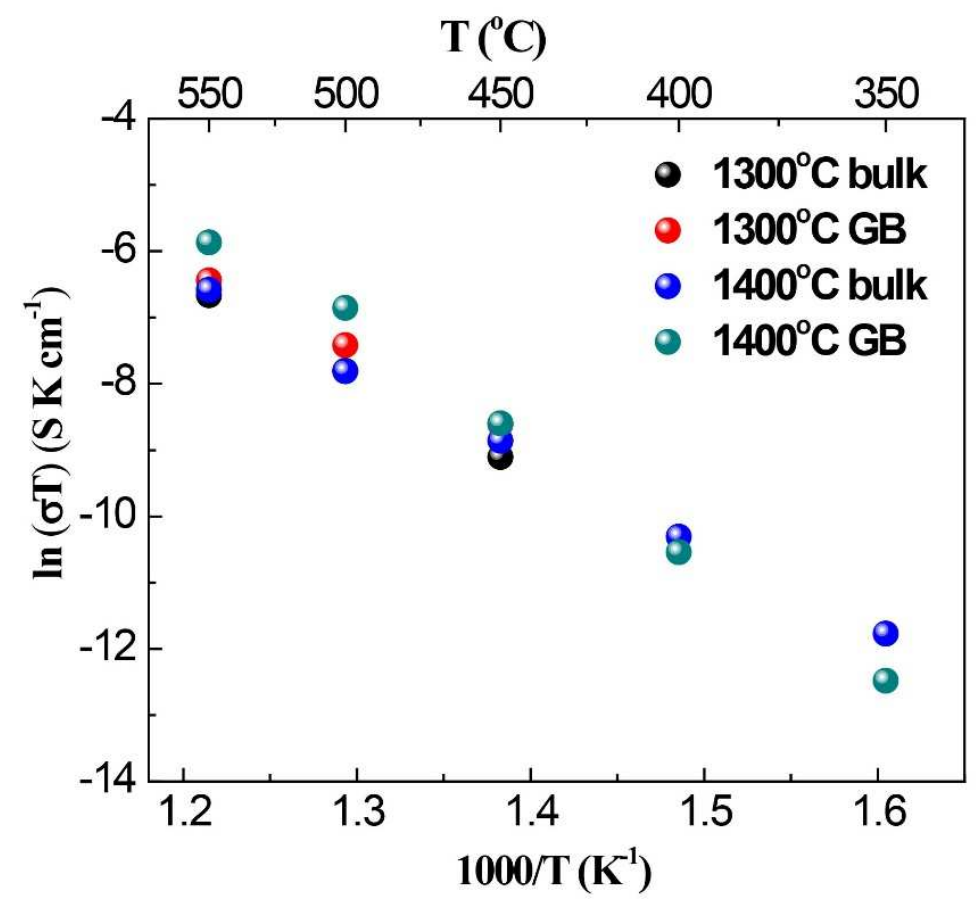

Fig. 7 Comparison of the bulk and grain boundary (GB) conductivity in wet $\mathrm{N}_{2}$ for the BZY samples sintering at 1300 and $1400^{\circ} \mathrm{C}$. 
Fig. 8
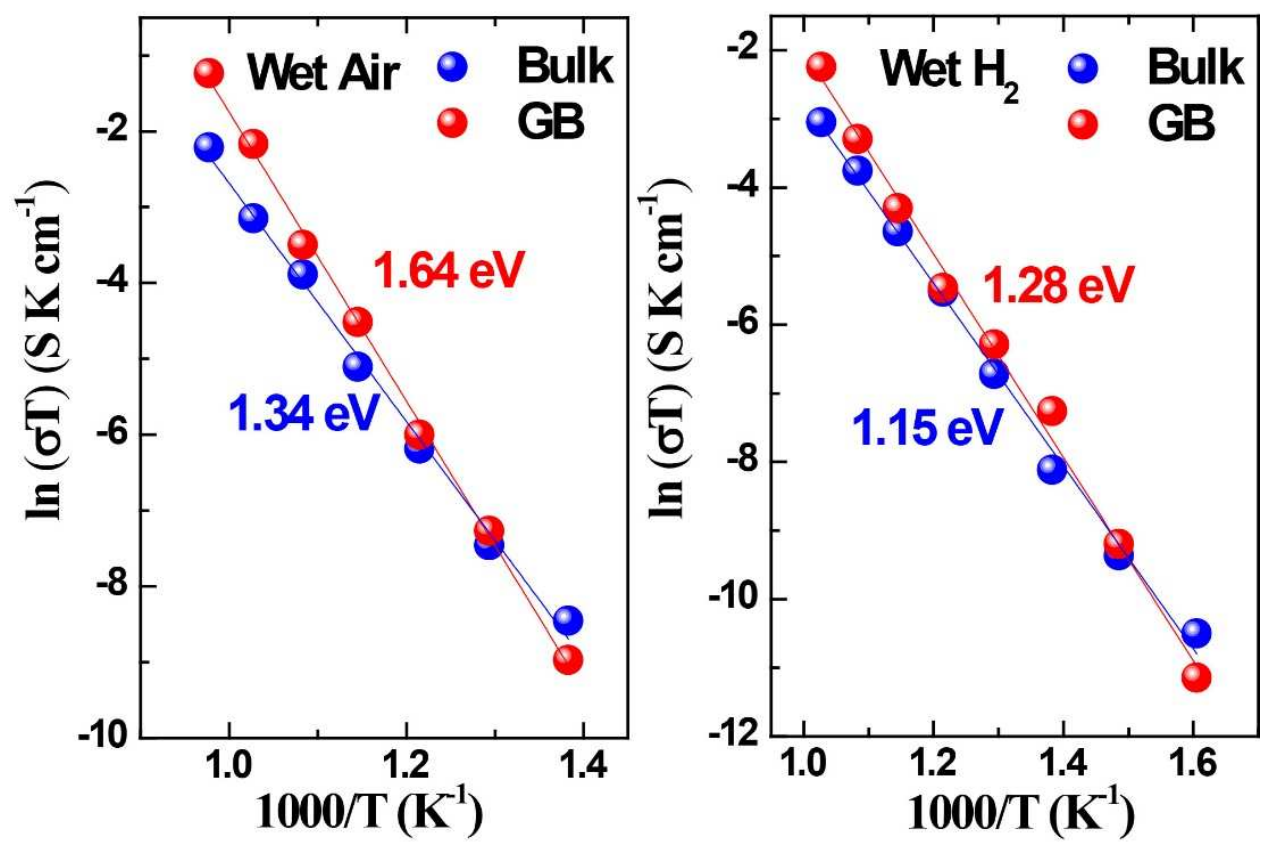

Fig. 8 Bulk and grain boundary (GB) conductivity for BZY sample sintered at $1400^{\circ} \mathrm{C}$. 